\title{
Hemifacial Spasm and Craniovertebral Anomaly
}

\author{
F.B. Maroun, J.C. Jacob, B.K.A. Weir and M.A. Mangan
}

\begin{abstract}
Two patients with congenital anomaly of the craniovertebral junction causing disabling hemifacial spasm (HFS) are presented. In one patient, complete cessation of the HFS occurred for a period of two years following simple bony decompression of the craniovertebral junction raising unanswered questions as to the exact pathogenesis of HFS. Eventually both patients required microvascular decompression at the root entry zone of the facial nerve.
\end{abstract}

RÉSUMÉ: Spasme hémifacial et anomalie crâniovertébrale Les cas de deux malades souffrant de spasme hémifacial dû à une anomalie congenitale de la charnière crâniovertébrale sont présentés. Chez l'un des malades, une abolition complète du spasme hémifacial durant deux ans a été notée après une décompression osseuse simple de la charnière crâniovertébrale, soulevant des questions restées sans réponse sur la pathogenèse exacte du spasme hémifacial. Eventuellement les deux malades ont nécessité une décompression microvasculaire du nerf facial à son émergence du tronc cérébral.

Can. J. Neurol. Sci. 1990; 17:424-426

Hemifacial spasm (HFS) is a relatively uncommon clinical problem. To our knowledge, the association of HFS with craniovertebral anomaly has not been described. Compression of the facial nerve in its intracranial or extracranial segment by a vascular loop has been reported in a large number of patients. ${ }^{1-4}$ The improvement of HFS following decompression of the foramen magnum in one of our patients, without microvascular decompression of the facial nerve, raises the possibility that other pathogenic factors may be involved in the genesis of hemifacial spasm.

\section{Patient 1}

A 30-year-old automobile body repair mechanic presented in July 1976 with episodic, diffuse headaches which had increased in severity over the preceding two years. He had also been aware of variable twitch-like movements involving the left side of the face.

On examination, his head appeared large. The neck was markedly short with restricted movements in all directions. Prominent HFS involving the left orbicularis oculi, oris muscles and to a lesser degree, the left platysma muscle, was evident. There was no limb weakness, but symmetrical hyperreflexia was more marked in the legs than the arms and the plantar responses were flexor. Radiological studies (Figure 1 and 2) showed marked platybasia, basilar invagination, assimilation of atlas with the occiput, and a tortuous anterior inferior cerebellar artery (AICA). Unroofing of the foramen magnum and removal of the arch of the atlas was carried out. The surgical findings consisted of a stenosed foramen magnum, assimilation of atlas to the occiput, and downward displacement of the tonsils to the level of $\mathrm{C}-1$. No attempt was made to remove the cerebellar tonsils or explore the cerebello-pontine angle. Complete cessation of HFS was noted immediately after surgery and for a period of 2 years when it reappeared but with less severity than preoperatively. Seven years postoperatively, HFS became continuous and

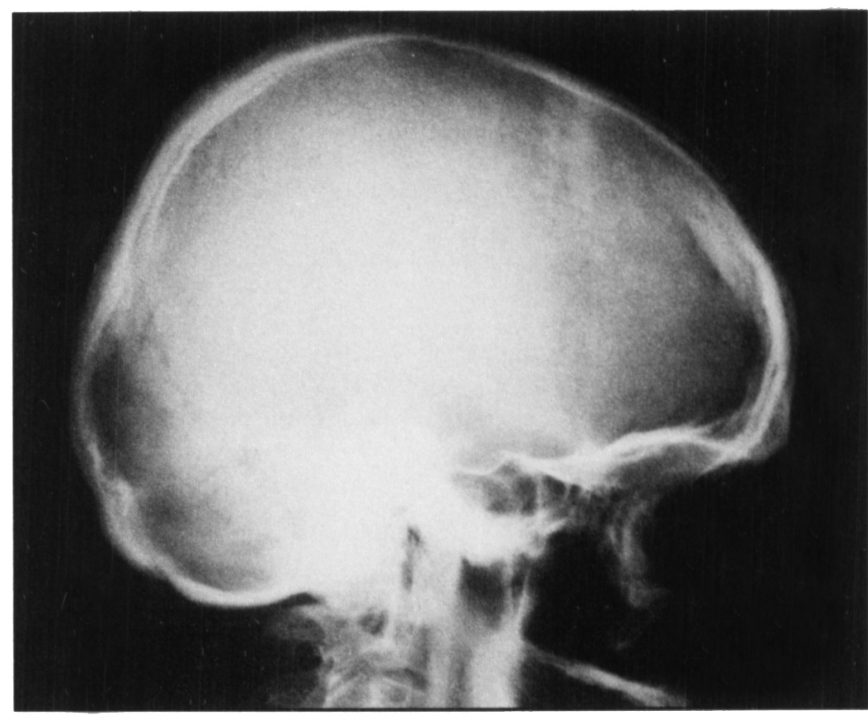

Figure I - Patient I - Lateral skull $x$-ray showing platybasia and hasilar invagination.

severe involving the upper and lower face with occasional spread to the platysma muscle.

Microvascular decompression was carried out using teflon pledgets separating a large tortuous loop of the anterior inferior cerebellar artery from the brain stem. Immediately after surgery and up to the last follow up one year after, there was marked improvement in both the frequency

From the Divisions of Neurosurgery, Neurology and the Department of Radiology, Memorial University of Newfoundland, St. John's, Newfoundland (F.B.M., J.C.J., M.A.M.) and the Division of Neurosurgery, University of Alberta, Edmonton, Alberta (B.K.A.W.)

Received November 15, 1989. Accepted in final form July 16, 1990

Reprint requests to: Dr. F.B. Maroun, 12 Gleneyre Street, St. John's, Nfld. A1A 2M7 


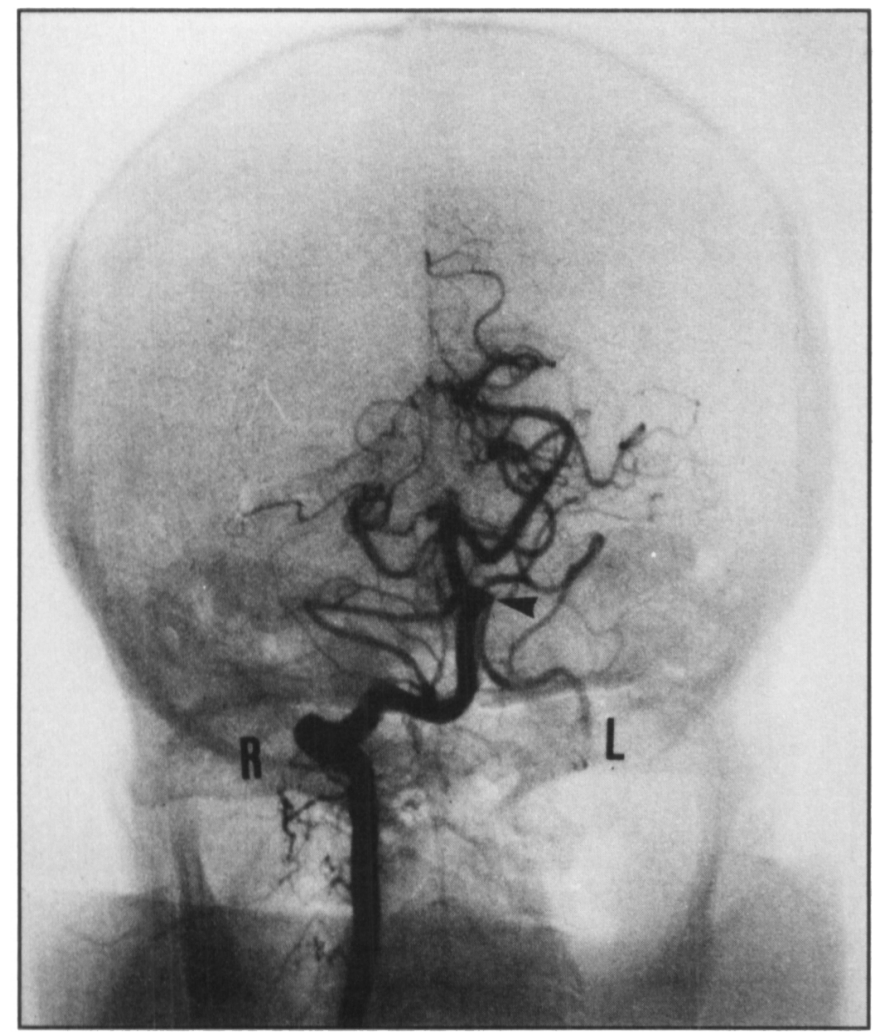

Figure 2 - Patient 2 - AP angiogram: Tortuous AICA and near common origin of both AICA and PICA on the left. (Arrow)

and the severity of the spasms (improvement estimated by the patient at $80 \%$ ).

\section{Patient 2}

A 31-year-old female was hospitalized with a three year history of left hemifacial spasm. Shortly after birth, she had been operated on for an occipital encephalocele. The spasm began in the left lower lid musculature and had progressively involved the entire left face. It was triggered by smiling or assumption of the recumbent position. The spasm was also precipitated by bright light and normal facial movements.

On physical examination she had obvious left hemifacial spasms and a very short neck with marked limitation of flexion and extension of the head.

Plain skull $\mathrm{x}$-rays (Figure 3), CT and MRI studies demonstrated a small bony defect in the mid occipital region without associated soft tissue abnormality. She had an incomplete anterior and posterior ossification of the ring of the first cervical vertebra. The 2 nd and 3 rd and the $4 \mathrm{th}$, 5th and 6 th vertebrae were fused. There was no downward herniation of the tonsils. At surgery a vascular loop at the anterior inferior cerebellar artery was found compressing the root exit zone of the 7th cranial nerve. Teflon pledgets were used to separate it from the brain stem. Initially, she was somewhat improved but the hemifacial spasm persisted, so a second operation was performed two weeks later and further pledgets of teflon were used to displace the vascular loop. Following this, the hemifacial spasms were markedly improved and disappeared completely after about one month. At six months postoperative follow-up, there had been no recurrence.

\section{Discussion}

Despite advances in the treatment of HFS, the pathophysiology of the disorder is debated. ${ }^{5}$ Some authors believe that the offending lesion is within the facial nerve nucleus or in the nerve proximal to the stylomastoid foramen. However, HFS is not affected by acute onset of hemiplegia and symptoms

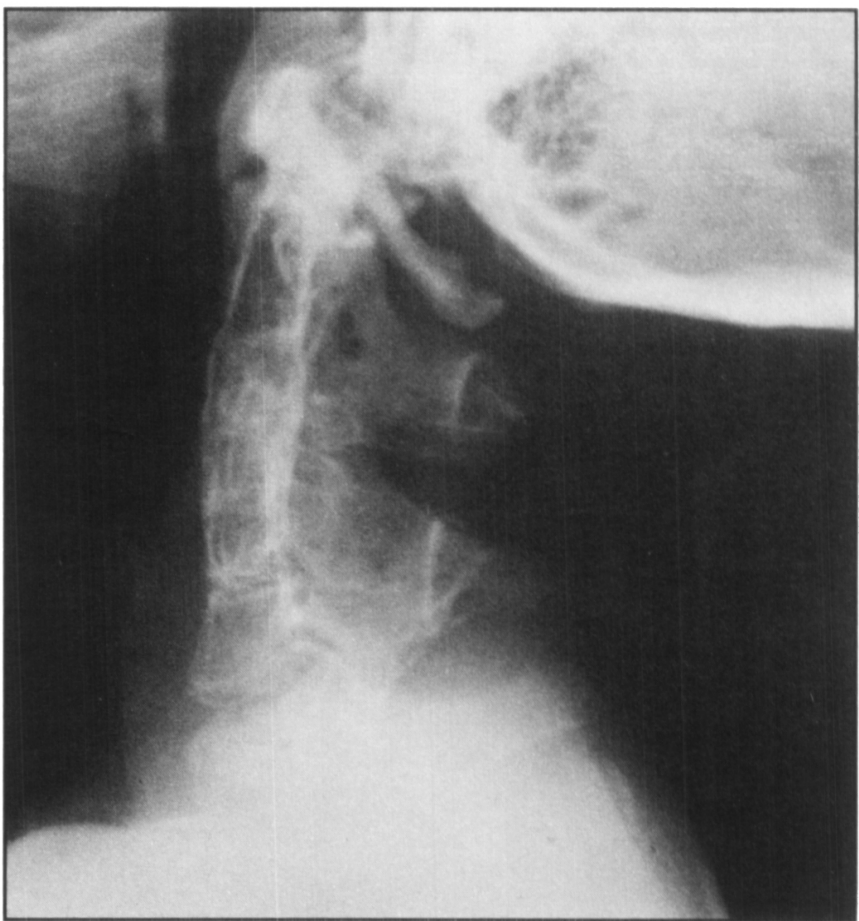

Figure 3 - Patient 2 - Lateral plain cervical spine $x$-ray show's fusion of the 2 nd and $3 r d$ and $4 t h$, 5th and 6th vertebral bodies.

recur following nerve transection and regeneration distal to the foramen. Others invoke swelling and/or constriction of the nerve in the facial canal. Neither view provides an explanation for a specific cause. A mechanical cause compressing the facial nerve at the root entry zone is now generally accepted. Neoplasms of the cerebellopontine angle or tumours of the facial nerve can cause HFS but the reported cases are extremely rare ${ }^{6,7}$ More com-monly, the compressive element of the facial nerve is vascular (arterial loop or dilatation, veins, aneurysms and AV malformations). $3.4,6.8 .9 .10 .11$ A rare mechanical cause of bilateral hemifacial spasm was described by Gardner and Dohn in a patient with severe Paget's disease and basilar impression. ${ }^{12}$

Jannetta remarks "as we age, our arteries elongate and our brains sag". ${ }^{4}$ As a consequence of these processes, redundant arterial loops and bridging of intrinsic hindbrain veins may cause "cross compression". Although the majority of patients with HFS are in the fifth decade of life, the disorder has been described in children and young adults. ${ }^{13,2,14,15}$ In these patients, congenital vascular anomalies at the base of the brain compressing or distorting the facial nerve root entry zone are seen without evidence of arteriosclerosis or brain atrophy.

One of the major criticisms of the vascular theory has been the number of negative explorations. ${ }^{16.17 .18} \mathrm{Also}$, from the therapeutic point, why does HFS without obvious vascular pathology improve following wrapping or manipulation of the facial nerve? Is the relief of HFS a consequence of "trauma" inflicted during surgical exposure, or a delayed one due to circumferential fibrosis by the prosthesis?

In a review article discussing the role of microvascular compression in different clinical entities, Adams ${ }^{19}$ concludes that the evidence to support the vascular hypothesis is "believed to be insufficient and unconvincing". The role of trauma to a "sensitive zone of the cranial nerve" is again emphasized. The most 
important point raised by Adams is the fact that trigeminal and glossopharyngeal neuralgia, hemifacial spasms and disorders of the eighth nerve can all be cured by section of the affected nerve except for spasmodic torticollis which, in his mind, is the "most obvious candidate to prove microvascular compression".

In our first patient whose hemifacial spasms disappeared for two years following bony decompression of the craniovertebral junction, a few points can be raised: a) Is it due to further downward shift of brain stem structures? or b) Is it due to a change in position of blood vessels within the posterior fossa which in Chiari malformation and other craniovertebral bony anomalies are usually "crowded" and abnormally situated? and c) Do patients with facial spasm but no obvious vascular abnormality represent perhaps a form fruste of vertebrocranial anomaly and/or Chiari malformation?20

If the vascular etiology for the genesis of HFS is favoured, it is surprising that HFS is relatively uncommon in the light of anatomical data suggesting the intimate relations between the facial nerve and the vasculature of the base of the brain.21 However, as Jannetta and others emphasize, the offending vessel should produce a cross compression and it must be at the nerve root entry zone, i.e. at the junction of the central and peripheral myelin. From these observations and in addition to the points already discussed, we would like to postulate two hypotheses. First, the vascular loop may be an anatomical anomaly and age may play a significant role in the occurrence of spasm. Secondly, subtle changes in posterior fossa and brain stem structures (i.e. form "fruste" of craniovertebral anomaly and Chiari malformation) may play a role in the genesis of HFS.

\section{REFERENCES}

1. Auger RG, Piepgras DG, Laws ER. Hemifacial spasm: Results of microvascular decompression of the facial nerve in 54 patients. Mayo Clin Proc 1986; 61: 640-644.

2. Ehni G, Woltman HW. Hemifacial spasm: review of one hundred and six cases. Arch Neurol Psychiatry 1945; 53: 205-211.

3. Jannetta PJ, Abbasy M, Maroon JC, et al. Etiology and definitive microsurgical treatment of hemifacial spasm. J Neurosurg 1977; 47: $321-328$.
4. Jannetta PJ. Neurovascular compression in cranial nerve and systemic disease. Ann Surg 1980; 192: 518-522.

5. Maroon JC. Hemifacial spasm - a vascular cause. Arch Neurol 1978; 35: 481-483.

6. Loeser JD, Chen J. Hemifacial spasm: treatment by microsurgical facial nerve decompression. Neurosurgery 1983; 13: 141-146.

7. Schloss MD, Bebear JP. Hemifacial spasm: importance of a complete investigation. J Otolaryngol 1976; 5: 319-330.

8. Maroon JC, Lunsford LD, Deeb ZL. Hemifacial spasm due to aneurysmal compression of the facial nerve. Arch Neurol 1978; 35: 545-546.

9. Moore AP. Postural fluctuation of hemifacial spasm - case report. J Neurosurg 1984; 60: 190-191.

10. Piatt JH, Wilkins RH. Treatment of tic douloureux and hemifacial spasm by posterior fossa exploration: therapeutic implications of various neurovascular relationship. Neurosurgery $1984 ; 14: 462-$ 471.

11. Rand RW. Gardner neurovascular decompression for hemifacial spasm. Arch Neurol 1982; 39: 510-511.

12. Gardner WJ, Dohn WF. Trigeminal neuralgia - hemifacial spasm Paget's disease: significance of their association. Brain 1966; 89: 555-612.

13. Jho HD, Jannetta PJ. Hemifacial spasm in young people treated with microvascular decompression of the facial nerve. Neurosurgery 1987; 20: 767-770.

14. Shaywitz BA. Hemifacial spasm in childhood treated with Carbamazepine. Arch Neurol 1974; 31: 63.

15. Ronen GM, Donat JR, Hill A. Hemifacial spasm in childhood. Can J Neurol Sci 1986; 13: 342-343.

16. Fabinyi CGA, Adams CBT. Hemifacial spasm: treatment by posterior fossa surgery. J Neurol Neurosurg Psychiatry 1978; 41 : 829833.

17. Kaye AH, Adams CBT. Hemifacial spasm: a long term follow-up of patients treated by posterior fossa surgery and facial nerve wrapping. J Neurol Neurosurg Psychiatry 1981; 55: 1100-1103.

18. Aokin N. Resolution of hemifacial spasm after posterior fossa exploration without vascular decompression. Neurosurg 1986; 18: 478-479.

19. Adams CBT. Microvascular compression: an alternative view and hypothesis. J Neurosurg 1989; 57: 1-12.

20. Maroun FB, Jacob JC, Mangan M. Hemifacial spasm. Neurosurgery $1987 ; 20$ : 994-995.

21. Sunderland S. Neurovascular relations and anomalies at the base of the brain. J Neurol Neurosurg Psychiatry 1948; 11: 243-257. 